\title{
Motor Learning and Motor Development as a Motor Competence Problem Throughout Lifespan
}

\author{
Maria Teresa Cattuzzo* \\ University of Pernambuco, Brazil \\ *Corresponding author: Maria Teresa Cattuzzo, PhD, University of Pernambuco, Recife, Brazil
}

Submission: :

\section{Opinion}

Motor learning and motor development are processes dealing with motor behavior changes through time. In fact, both phenomena are be distinguished when some new behavior is overt in observable motor actions. In motor development, the changes are associated with given lifetime periods and in the motor learning the changes are associated with some specific practice experience. Still, for both phenomena, it is not enough to perform a new action, but such action must to meet it aim reliably, i.e., the performer must be frequently successful, even if there are demands challenging him/ her. Thus, motor learning and motor development deal with the motor skills acquisition and/or their adjustments, in an elaborative and incremental open-ended trajectory throughout lifespan [1].

Some scholars must be accessed when one talks about motor skill. In one most remarkable book to motor behavior field written in 1940's decade, but acknowledged some decades later, Bernstein stated that the dexterity/skill, is the ability to adequately solve any emerging motor problem correctly, quickly, rationally and resourcefully. Elliott \& Connolly [2] offered a um more piece of the puzzle about what is the skill by assuming it is "an ability to achieve defined goals with an efficiency beyond that of inexperienced person" (p.135) and hypothesizing that "... skill entails an ability a competence - which underlies assessed performance on specific tasks" (p. 135/136). For Elliott \& Connolly [3] competence is related to the organization underlying the child's behavioral adjustment to his/her environment.

Following the Bernstein's and Elliott \& Connolly's [3] theoretical propositions, Keogh [4], ingeniously and beautifully, offered a more encompassing view about skill and motor competence by adding the explanations about the consistency and the constancy of movement, both expressions of motor competence. Movement consistency is the competency to perform sequences of movement patterns, which are suitable for solving everyday motor problems, e.g., standing up, walking, grasping or other elementary motor skills. In fact, for the infant or young child to meet such movement consistency is the main problem to be solved at that time [4]. In order to show stable motor patterns, consistency is the first and main expression of motor competence in childhood. Next, a harder problem to human motor competence is to achieve the movement constancy, i,e.; the flexible use of the movement consistencies in a variety of circumstances. In such view, consistency and constancy are closed linked: the constancy is only possible if there is consistency of movements firstly, and movement consistency must be increased when a movement patterns can be fitted in numerous circumstances, as movement constancy develops. In sum, in a competent motor performance, the consistency and the constancy are crucial and harmonizing. Still, if the constancy follows the consistency, one can expect the operational measure of motor competence must to contemplate such developmental issue [5].

In 2008, one very hot paper to motor behavior field titled "A Developmental Perspective on the Role of Motor Skill Competence in Physical Activity: An Emergent Relationship", written by Stodden et al. [6], recovered the motor competence study in a very strategic way, by relating it with the physical activity, perceived motor competence and physical fitness. They proposed an operational definition to motor competence, as the proficiency in fundamental motor skills involving object control and locomotor skills. This definition is very fitted to theoretical model proposed, as well as it is aligned with the empirical data from literature at that time which based the proposal. In that paper, Stodden et al. [6] explored the early and later childhood phases of life, and for typical children in such phases to meet the consistency in gross fundamental motor skills is a genuine problem to solve. In fact, the main tools used to assess motor competence in childhood deals with gross motor performance, e.g., Test of Gross Development 2nd edition, (TGMD2) [7] and Körper ko ordinations test für Kinder (KTK) [8]. One should to take care to use these two tools interchangeably, because they deal with different aspects of gross motor competence, as recently remarked (Ré et al. [9]). Conversely but complementary, some researchers have proposed the importance to include the fine motor skills in the theoretical definition of motor competence, like D'Hondt et al. [10] and Sigmundson et al. [11].

The propositions of the Stodden et al. [6] has been confirmed markedly. Robinson et al. [12] in a critical review, showed the success of that theoretical model to the scientific community. This renewed view about the emergent relationship (as the article's title deliveries) is a change of view between physical activity and motor behavior areas. The closed link between energetic element 
(physical activity) and control element (motor competence) in the human system was really important change in the perspective, if one wants to cope with the health like a systemic subject. The singular model tailored by Stodden and friends, brings more two important variables, the perceived motor competence and health related physical fitness. The choosing of these variables was not trivial, since it was based in empirical results from studies with motor behavior and health. In accord to Hopkins et al. [13] patterns of human behavior can be explained by changes in the fundamental patterns of coexistence among various components of the developing system; when a component changes, a new state of coexistence can emerge, a state in which the observable behavior consists of new and striking properties [13].

But, in my opinion, the beauty and power of the model was to show as the elements in interaction and their aim outcome (the weight status) back feeds the system. This feedback mechanism, named positive feedback typical from complex and open systems theory [14], works reinforcing the direction of the consequence, in a "gain-gain" mode: if the interaction elements results in a negative outcome (not healthy weight status) this tendency will be reinforced, i.e., the negative spiral of engagement in the model; conversely, if the interaction results in a positive outcome (healthy weight status), this tendency has higher chance to remain, i.e., the negative spiral of engagement. In sum, to explore the interactions between the motor behavioral elements in childhood, with special emphasis on the coexistence between the level of physical activity and motor competence, tends to be an important item in a research agenda that considers that health incorporates a style of active life and that it can be established early in the life of the individual.

However, some issue points must be elected if one wants to continue built a true developmental theory about the relationship between motor competence and health outcomes. For example, urges to examine the developmental approach assumed by that model because, as such, it should be to explore the motor competence in others phases of life, covering the cycle life full. By assuming the life span examination an important issue is about the operational definition of motor competence, which, needs to include both consistency as constancy, gross and fine gross skills, throughout lifespan. Recently, Sigmundson et al. [11] have proposed a battery to assess motor competence from childhood to old age, a very promisor one, which need to be more investigated. In fact, the phenomenon of motor competence revisited seems to be able to give rise to a new milestone in the history of motor behavior studies, replacing the so-called process-oriented period [15]. Maybe a new denomination is needed, but that's a subject for another article.

\section{References}

1. Ford DH, Lerner RM (1992) Developmental systems theory: An integrative approach. Sage Publications Inc, USA.

2. Bernstein NA (1996) Dexterity and its development. In: Latash ML, Turvey MT (Eds.), Lawrence Erlbaum Associates Inc, Hillsdale, NJ, USA.

3. Elliott J, Connolly K (1974) Hierarchical structure in skill development. In: Connolly KJ, Bruner JS (Eds.), The growth of competence. Academic Press, London, UK, pp. 109-127.

4. Keogh JF (1977) The study of movement skill development. Quest 28(1): 76-88.

5. Newell KM (1996) Change in movement and skill: Learning, retention, and transfer. In: Latash ML, Turvey MT (Eds.), Dexterity and its development. Mahwah, Erlbaum, USA, pp. 393-429.

6. Stodden DF, Goodway JD, Langendorfer SJ, Roberton MA, Rudsill ME, et al. (2008) A developmental perspective on the role of motor skill competence in physical activity: an emergent relationship. Quest: 60(2): 290-306.

7. Ulrich DA (2000) Test of gross motor development-2. Austin, TX, USA.

8. Kiphard EJ, Schilling F (1974) Körperko ordinations test für Kinder [Body coordination test for children]. Manual, Beltz Test GmbH, Weinheim, Germany.

9. Ré AH, Logan SW, Cattuzzo MT, Henrique RS, Tudela MC, et al. (2018) Comparison of motor competence levels on two assessments across childhood. Journal of sports sciences 36(1): 1-6.

10. D'Hondt E, Deforche B, De Bourdeaudhuij I, Lenoir M (2009) Relationship between motor skill and body mass index in 5-to 10-year-old children. Adapt Phys Activ Q 26(1): 21-37.

11. Sigmundsson H, Lorås H, Haga M (2016) Assessment of motor competence across the life span: Aspects of reliability and validity of a new test battery. SAGE Open 6(1): 2158244016633273.

12. Robinson LE, Stodden DF, Barnett LM, Lopes VP, Logan SW, et al. (2015) Motor competence and its effect on positive developmental trajectories of health. Sports Medicine 45(9): 1273-1284.

13. Hopkins B, Kalverboer AF, Geuze RHM (1993) Epilogue: description versus explanation. In: Kalverboer AF, Geuze RHM (Eds.), Motor development in early and later childhood: longitudinal approaches. Cambridge University Press, UK.

14. Bertalanffy LV (1950) The theory of open systems in physics and biology. Science 111(2872): 23-29.

15. Clark JE, Whitall J (1989) What is motor development? The lessons of history. Quest 41(3): 183-202.
Creative Commons Attribution 4.0 International License

For possible submissions Click Here

\section{Submit Article}

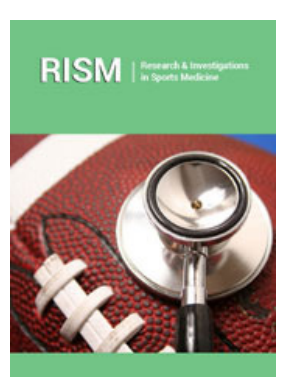

Research \& Investigations in Sports Medicine

\section{Benefits of Publishing with us}

- High-level peer review and editorial services

- Freely accessible online immediately upon publication

- Authors retain the copyright to their work

- Licensing it under a Creative Commons license

- Visibility through different online platforms 